\title{
Adjunctive Intravitreal Bevacizumab with Vitrectomy for Diabetic Vitreous Hemorrhage
}

\author{
Sayed A. Mahfouz, Mahmoud M. Khalil, Mohammed A. Elbahr \\ Department of ophthalmology, Faculty of Medicine, Al-Azhar University, Cairo, Egypt.
}

\begin{abstract}
Background: Postoperative vitreous hemorrhage (VH) following pars plana vitrectomy (PPV) for proliferative diabetic retinopathy (PDR) is a common event, with a reported incidence of $29 \%$ to $75 \%$.This complication delays visual rehabilitation, interferes with fundus examination, and may necessitate additional surgical procedures. Vascular endothelial growth factor (VEGF) is an angiogenic mitogen, and the involvement of VEGF in PDR has been suggested by studies that have demonstrated that VEGF concentrations were markedly elevated in both vitreous and aqueous fluids of patients with active PDR compared with samples from patients without diabetes, with NPDR, or with quiescent PDR. Bevacizumab (Avastin ${ }^{\circledR}$, Genentech, Inc., South San Francisco, CA) is a full-length recombinant humanized monoclonal antibody that binds to all isoforms of VEGF.
\end{abstract}

Aim of the Work: to evaluate the safety and efficacy of intravitreal bevacizumab (IVB) at the end of vitrectomy operation for prevention of postoperative rebleeding in patients with diabetic vitreous hemorrhage.

Patients and Methods: The study included 20 eyes of 20 patients undergoing PPV for severe non-clearing vitreous hemorrhage for more than 1 month. Eligible eyes were randomly assigned to one of two groups: Group A (10 eyes) did not receive any intravitreal injection and Group B (10 eyes) received $1.25 \mathrm{mg}$ IVB injection at the end of surgery. All patients were subjected to complete history taking and full ophthalmic examination including best-corrected visual acuity, anterior segment examination, fundus examination and Bscan ultrasonography was performed. All patients underwent three-port pars plana vitrectomy using 23-gauge instrumentation under local anesthesia. At the end of surgery, fluid-air exchange was performed and the intraocular air is left as tamponade in selected cases. The follow up period occurred over 1 week, 1 month and 3 months. The main outcome measures were occurrence of vitreous hemorrhage and BCVA.

Results: At 1 month after surgery, the incidence of early postoperative VH was $30 \%$ and $20 \%$ in Group A and $\mathrm{B}$, respectively $(\mathrm{p}=0.641)$. Mild vitreous hemorrhage (grade 1 ) was the major component of early VH at 1 month (20\% of $30 \%$ and $10 \%$ of $20 \%$, in Group A and B, respectively). Analysis of changes in the mean BCVA at 1 month after surgery showed significant improvement from the preoperative BCVA in all study groups, the mean differences between pre-BCVA (Log MAR) and post BCVA (Log MAR) among the studied groups was $0.865 \pm 0.351$ with statistically significant difference between the two groups $(p=0.000)$.the mean differences between pre-BCVA (Log MAR) and post BCVA (Log MAR) among the studied groups was 0.865 \pm 0.351 with statistically significant difference between the two groups $(\mathrm{p}=0.000)$. At 3 months after surgery, the incidence of late postoperative $\mathrm{VH}$ was $20.0 \%$ and $0.00 \%$ in Group A and B, respectively, with no significant difference between the two groups $(\mathrm{P}=0.237)$. Again, analysis of changes in the mean $\mathrm{BCVA}$ at 3 months after surgery showed significant improvement to $1.080 \pm 0.2098$ and $0.870 \pm 0.17767$ in Group A and $B$, respectively, with statistically significant difference between the two groups ( $p$ >0.027).

Conclusion: The incidence of late postoperative vitreous hemorrhage is lower than that of early postoperative vitreous hemorrhage and is not affected by intraoperative intravitreal bevacizumab injection and Adjunctive use of intravitreal bevacizumab with pars plana vitrectomy for complications of PDR is safe and well-tolerated with no serious ocular or systemic adverse events.

Keywords: Diabetic Vitreous Hemorrhage, Intravitreal Bevacizumab, pars plana vitrectomy.

\section{INTRODUCTION}

Diabetic retinopathy (DR) is a leading cause of blindness among persons aged 20-64 years in the United States (US) and is the most common complication of diabetes, after a duration of 10 years, about $7 \%$ of persons with diabetes have retinopathy, rising to $90 \%$ after 25 years, in persons diagnosed with diabetes before the age of 30 years, the prevalence of proliferative diabetic retinopathy (PDR) is around 25\% after 15 years and 55\% after 20 years ${ }^{(1)}$. In 2002, WHO reported that DR caused $4.8 \%$ of blindness globally ${ }^{(2)}$.
Postoperative vitreous hemorrhage ( $\mathrm{VH})$

following pars plana vitrectomy (PPV) for proliferative diabetic retinopathy (PDR) is a common event, with a reported incidence of $29 \%$ to $75 \%{ }^{(3)}$.

This complication delays visual rehabilitation, interferes with fundus examination, and may necessitate additional surgical procedures. Although the source is often not identifiable, etiologies of early postoperative $\mathrm{VH}$ include dispersion of residual blood from the peripheral vitreous skirt or retinal surface into the vitreous cavity, remnants of fibrovascular tissues, and 
intraoperative iatrogenic injury of retinal blood vessels, Sources of late postoperative $\mathrm{VH}$ include fibrovascular proliferation from sclerotomy sites, anterior hyaloidal fibrovascular proliferation, and neovascularization of residual fibrovascular tissue, the iris or the angle ${ }^{(4)}$.

Vascular endothelial growth factor (VEGF) is an angiogenic mitogen, and the involvement of VEGF in PDR has been suggested by studies that have demonstrated that VEGF concentrations were markedly elevated in both vitreous and aqueous fluids of patients with active PDR compared with samples from patients without diabetes, with NPDR, or with quiescent PDR ${ }^{(5)}$ and that VEGF was expressed in fibrovascular tissues obtained from PDR patients ${ }^{\left({ }^{(}\right)}$.

Bevacizumab (Avastin ${ }^{\circledR}$, Genentech, Inc., South San Francisco, CA) is a full-length recombinant humanized monoclonal antibody that binds to all isoforms of $\operatorname{VEGF}^{(7)}$.

Intravitreal bevacizumab has been reported to induce rapid regression of retinal and iris neovascularization in proliferative diabetic retinopathy (PDR). Further, presurgical administration of intravitreal bevacizumab may reduce intraoperative bleeding during membrane dissection in PDR with traction retinal detachment and may also reduce the occurrence of residual blood clots. The combined effects would thus enhance early clear-up of vitreous opacity from clot lysis and recurrent retinal bleeding ${ }^{(8)}$.

It has been suggested that intravitreal bevacizumab injection at the end of a surgery may decrease postoperative vitreous hemorrhage since it can potentially reduce bleeding from residual fibrovascular tissues ${ }^{(9)}$.

\section{AIM OF THE WORK}

This study aims to evaluate the safety and efficacy of intravitreal bevacizumab (IVB) at the end of Vitrectomy operation for prevention of postoperative rebleeding in patients with diabetic vitreous hemorrhage.

\section{PATIENTS AND METHODS}

This study comprised of 20 eyes with persistent diabetic vitreous hemorrhage for more than one month. The patients were selected from the outpatient ophthalmology clinic of Al-Azhar university hospitals. All surgical procedures and follow up carried out at Al-Azhar university hospitals. Patients were divided into two groups:
Group (A): (Control group): ten eyes underwent pars plana vitrectomy and left on air without injection of IVB.

Group (B): Ten eyes underwent pars plana vitrectomy and left on air with IVB (1.25 $\mathrm{mg} / 0.05 \mathrm{ml}$ ) injected at the end of vitrectomy.

\section{Study Design}

A prospective interventional randomized study. It was approved by the ethical board of AlAzhar University and an informed written consent was taken from each participant in the study.

\section{Patient's selection}

A) Inclusion criteria: Persistent diabetic vitreous hemorrhage for more than one month.

Phakic eye (either clear lens or faint cataract that doesn't interfere with posterior segment visualization) or pseudophakic more than three months.

B) Exclusion criteria: Neovascular glaucoma. Retinal detachment (Tractional or Rhegmatogenous) or advanced fibrovascular proliferation. Panretinal photocoagulation within the previous three months. Abnormal blood coagulation. Patients with blood disease.

\section{Preoperative evaluation:}

History Taking: Age and sex. Duration and type of diabetes mellitus (type 1 or 2), drugs used for control of blood glucose level, as well as the current status of glycemic control. Onset, course and duration of visual complaints (diminution of vision, floaters and/or photopsia). Past history of ocular diseases, ocular trauma, previous laser therapy or previous ocular surgery. Past history of systemic diseases especially hypertension, renal or cardiac diseases and abnormal blood coagulation.

Full Ophthalmic Examination: Estimation of best-corrected visual acuity (BCVA) using Landolt $\mathrm{C}$ chart or Illiterate $\mathrm{E}$ chart. Examination of the anterior segment using slit lamp biomicroscope. Clarity of the cornea, transparency of the crystalline lens, intra ocular lens (IOL) and presence of rubeosis iridis were recorded. Measurement of intraocular pressure (IOP) using Goldmann 
applanation tonometer. Fundus examination using indirect ophthalmoscope or slit lamp biomicroscop with a non-contact fundus lens (+78D, +90D). B-scan ultrasonography was done for all patients.

Postoperative follow-up: All patients were followed up on the first postoperative day, then first postoperative week, then first postoperative month and then then third postoperative month.

In the postoperative visits, all patients were subjected to the following: Estimation of Bestcorrected Visual Acuity (BCVA) using Landolt C chart or Illiterate $\mathrm{E}$ chart. Examination of the Anterior Segment using slit lamp biomicroscope. Presence and severity of corneal edema or anterior chamber reaction, as well as development or progression of lens opacity, the IOL position were recorded. Measurement of Intraocular Pressure (IOP) using Goldmann applanation tonometer. During the first postoperative week, estimation of IOP was done by air puff. Fundus Examination using indirect ophthalmoscope or slit lamp biomicroscope with a non-contact fundus lens $(+78 \mathrm{D},+90 \mathrm{D})$. B-scan ultrasonograpy if it is difficult to visualize the retina.

\section{Surgical procedure:}

Three-port Pars Plana Vitrectomy: Maximum pupillary dilation was obtained by topical application of tropicamide 1\% (Mydriacyl $^{\circledR}$ ) eye drops. All patients were operated upon under local anaesthesia, after proper control of their glycemic status.

Incisions and Creation of Sclerotomies:

A scleral tunnel at a 30-degree angle parallel to the limbus was created in the inferotemporal, superonasal and superotemporal quadrants. The trocar was removed and the cannula was left in place. The infusion cannula was placed in the inferotemporal quadrant, while the superonasal and superotemporal cannulas were used for the microsurgical instruments figure (1).

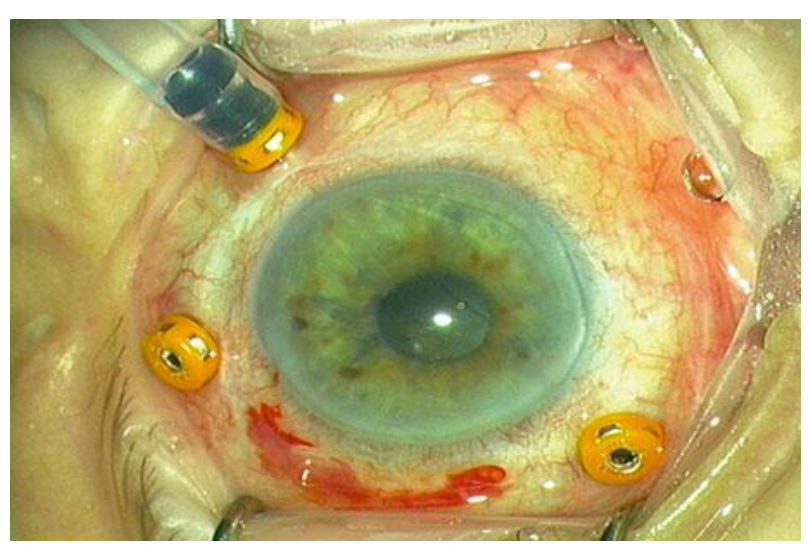

Figure (1): Sclerotomies in 23-gauge PPV.

Pars Plana Vitrectomy: The vitrectomy probe and the fiberoptic endoilluminator were introduced through the superior sclerotomies. After a core vitrectomy was performed, an opening in the posterior hyaloid connecting the preretinal space with the vitreous cavity was made with the vitrectomy probe. Preretinal blood was aspirated with a soft-tipped flute needle or with active suction of the vitrectomy probe. The posterior hyaloid was then excised for 360 degrees. If required, intravitreal injection of triamcinolone acetonide suspension $\left(\right.$ Kenacort $\left.^{\circledR}\right)$ was done to aid visualization of the posterior hyaloid. Peripheral vitrectomy was done to relieve anteroposterior traction. Vitreous base shaving with assisted scleral depression was performed with careful attention to remove as much residual blood as possible. Fibrovascular tissue and epiretinal membranes were removed to relieve tangential traction using a combination of segmentation and delamination techniques. Endolaser photocoagulation was done to complete panretinal photocoagulation up to the ora serrata. Fluid-air exchange was performed.

Closure of Sclerotomies: Gentle pressure was applied for few seconds to the sclerotomy sites using a cotton-tipped applicator after removal of the cannulas, and the conjunctiva above the sclerotomy was slightly displaced to disrupt the alignment between both entry sites. Lastly, the inferotemporal cannula, together with the infusion line, was removed in the same way.

Intravitreal Anti-VEGF Injection: For Group A patients, no intravitreal anti- VEGF injection was done. For Group B patients, intravitreal bevacizumab injection was performed through the pars plana at the end of vitrectomy after removal of the cannulas figure (2). 


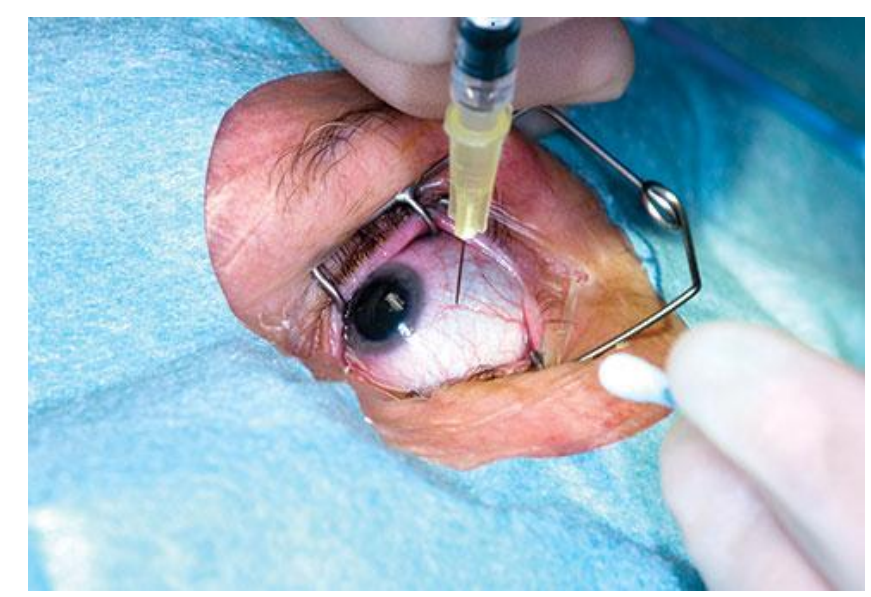

Figure (2): Intravitreal injection of anti-VEGF group.

\section{Statistical analysis}

The data were collected, revised, coded and entered to the statistical package for social science (SPSS) version 20. The qualitative data were presented as number and percentages while the quantitative data with parametric distribution were presented as mean, standard deviations and ranges.

Comparison between two paired groups with quantitative data and parametric distribution were done by using paired t-test.

Spearman correlation coefficients were used to assess the correlation between two quantitative parameters in the same group.

The confidence interval was set to $95 \%$ and the margin of error accepted was set to $5 \%$. So, the $\boldsymbol{P}$ Value (Probability) was considered significant as the following: $P>0.05$ means it is not statistically significant. $\mathrm{P}<0.05$ means it is statistically significant. $\mathrm{P}<0.01$ means it is statistically highly significant.

\section{RESULTS}

\section{The demographic and clinical data:}

The age of patients ranged from 45 to 60 years. The mean age in Group A and B was $55.40 \pm$ 4.142 and $54.40 \pm 3.169$ years, respectively. No statistically significant difference was detected between the two groups (p-value $=0.552)($ Table 1$)$.

Regarding sex, $60 \%$ and $70 \%$ of patients were males in Group A and B, respectively, with no statistically significant difference between the two groups $(\mathrm{P}=0.500)$ (Table 1$)$.

Regarding the type and duration of diabetes mellitus in each group, the mean of duration of DM in Group A and B was $17.10 \pm$ 7.852 and $15.90 \pm 5.109$, respectively with no statistically significant difference between the two groups, $\mathrm{P}$-value was $(\mathrm{P}=0.500)$ and $(\mathrm{P}=0.661)$ for type and duration of DM respectively (Table 1).

Regarding hypertension, the mean of duration of hypertension in Group A and B was $5.00 \pm 3.391$ and $4.167 \pm 2.563$, respectively. In each group there was no statistically significant difference between the two groups $(\mathrm{P}=0.500)$ (Table 1).

Regarding lens status, In Group A, 2 eyes (20\%) were pseudophakic, 5 eyes $(50 \%)$ had clear lens, while 3 eyes (30\%) had some degree of cataract. In Group B, 3 eyes (30\%) were pseudophakic, 4 eyes (40\%) had clear lens, while 3 eyes (30\%) had some degree of cataract, with no statistically significant difference between the two groups ( $\mathrm{P}=0.592)$ (Table 1).

Regarding history of PRP before three months, $70 \%$ and $50 \%$ of patients had previous PRP before three months in Group $\mathrm{A}$ and $\mathrm{B}$, respectively, with no statistically significant difference between the two groups $(\mathrm{P}=0.325)$ (Table 1).

Table (1): The demographic and clinical data.

\begin{tabular}{|c|c|c|c|}
\hline \multirow[b]{2}{*}{ Variables } & \multicolumn{3}{|c|}{ Studied groups } \\
\hline & $\begin{array}{c}\begin{array}{c}\text { Group A no IVB } \\
\text { injection } \\
\mathrm{N}=10(100 \%)\end{array} \\
\end{array}$ & $\begin{array}{c}\text { Group B IVB injection } \\
\mathrm{N}=10(100 \%)\end{array}$ & $\begin{array}{c}\text { Test of } \\
\text { significance }\end{array}$ \\
\hline $\begin{array}{l}\text { Sex: } \\
\text {-Male } \\
\text {-Female }\end{array}$ & $\begin{array}{l}6(60 \%) \\
4(40 \%)\end{array}$ & $\begin{array}{l}7(70 \%) \\
3(30 \%)\end{array}$ & $\begin{array}{c}\text { Chi-sq }=.220 \\
P=0.500\end{array}$ \\
\hline $\begin{array}{l}\text { Type of DM: } \\
\text { - type I DM } \\
\text {-type II DM }\end{array}$ & $\begin{array}{l}3(30 \%) \\
7(70 \%)\end{array}$ & $\begin{array}{l}2(20 \%) \\
8(80 \%)\end{array}$ & $\begin{array}{c}\text { Chi-sq }=.267 \\
P=0.500\end{array}$ \\
\hline $\begin{array}{l}\text { duration of DM: } \\
-10 \text { ys } \\
->20 \text { ys } \\
-10-20 \text { ys }\end{array}$ & $\begin{array}{l}1(10 \%) \\
8(80 \%) \\
1(10 \%)\end{array}$ & $\begin{array}{l}2(20 \%) \\
7(70 \%) \\
1(10 \%)\end{array}$ & $\begin{array}{c}\text { Chi-sq }=.400 \\
P=0.661\end{array}$ \\
\hline $\begin{array}{l}\text { Hypertension: } \\
\text {-Yes } \\
\text {-No }\end{array}$ & $\begin{array}{l}5(50 \%) \\
5(50 \%)\end{array}$ & $\begin{array}{l}6(60 \%) \\
4(40 \%)\end{array}$ & $\begin{array}{c}\text { Chi-sq }=.202 \\
P=0.500\end{array}$ \\
\hline $\begin{array}{l}\text { Lens status anterior } \\
\text { seg.examin: } \\
\text {-Clear lens } \\
\text {-Some degree of cataract } \\
\text {-Pseudophakia }\end{array}$ & $\begin{array}{l}5(50 \%) \\
3(30 \%) \\
2(20 \%)\end{array}$ & $\begin{array}{l}4(40 \%) \\
3(30 \%) \\
3(30 \%)\end{array}$ & $\begin{array}{c}\text { Chi-sq }=.311 \\
P=0.592\end{array}$ \\
\hline & \multicolumn{2}{|c|}{ Mean \pm Std. Deviation } & \\
\hline Age & $55.40 \pm 4.142$ & $54.40 \pm 3.169$ & $\begin{array}{c}\mathrm{t}=.606 \\
\mathrm{P}=0.552\end{array}$ \\
\hline duration of DM & $17.10 \pm 7.852$ & $15.90 \pm 5.109$ & $\begin{array}{c}\mathrm{t}=.405 \\
\mathrm{P}=0.690\end{array}$ \\
\hline Duration of hypertension & $5.00 \pm 3.391$ & $4.167 \pm 2.563$ & $\begin{array}{c}\mathrm{t}=.465 \\
\mathrm{P}=0.653\end{array}$ \\
\hline $\begin{array}{l}\text { History of PRP: } \\
\text { Yes } \\
\text { No }\end{array}$ & $\begin{array}{l}7(70 \%) \\
3(30 \%)\end{array}$ & $\begin{array}{l}5(50 \%) \\
5(50 \%)\end{array}$ & $\begin{array}{c}\text { Chi-sq }=0.833 \\
\mathrm{P}=0.325\end{array}$ \\
\hline
\end{tabular}

Preoperative Best Corrected Visual Acuity (BCVA) among the studied groups:

There was 1 eye $(10 \%)$ with BCVA $>0.5$ 1,4 eyes $(40 \%)$ with BCVA $->1-1.8$ and 5 eyes $(50 \%)$ with BCVA $->1.8$ in group $\mathrm{A}$, and 1 eye 
(10\%) with BCVA ->0.5-1, 5 eyes (50\%) with BCVA $>1-1.8$ and 4 eyes (40\%) with BCVA $>1.8$ in group $\mathrm{B}$, with no statistically significant difference between the two groups $(\mathrm{P}=0.895)$ (Table 2), and the mean standard deviation was $1.910 \pm 0.2283$ and $1.900 \pm 0.2494$ in group A and B respectively with no statistically significant difference between the two groups $(\mathrm{P}=0.927)$ (Table 3).

Table 2 shows comparison between the preoperative BCVA among the studied groups and in this table:

- $\leq 0.5 \log$ MAR corresponds to $\geq 6 / 18$ Snellen equivalent.

- $\quad>0.5-1.0 \log$ MAR corresponds to $6 / 60-<6 / 18$ Snellen equivalent.

- $\quad>1.0-1.8 \log$ MAR corresponds to $1 / 60-<6 / 60$ Snellen equivalent.

- $>1.8$ log MAR corresponds to <1/60 Snellen equivalent.

Table (2): Comparison between the preoperative BCVA among the studied groups.

\begin{tabular}{|c|c|c|c|}
\hline \multirow{2}{*}{ Variables } & \multicolumn{3}{|c|}{ Studied groups } \\
\cline { 2 - 4 } & $\begin{array}{c}\text { Group A no IVB } \\
\text { injection } \\
\text { N=10 100\% }\end{array}$ & $\begin{array}{c}\text { Group B IVB } \\
\text { injection } \\
\text { N=10 100\% }\end{array}$ & $\begin{array}{c}\text { Test of } \\
\text { significance }\end{array}$ \\
\hline pre-BCVA: & $1(10 \%)$ & $1(10 \%)$ & \\
$->0.5-1$ & $4(40 \%)$ & $5(50 \%)$ & Chi-sq=.222 \\
$\rightarrow 1-1.8$ & $5(50 \%)$ & $4(40 \%)$ & $\mathrm{P}=0.895$ \\
$\rightarrow>1.8$ &
\end{tabular}

Table (3): Mean difference between the studied groups as regard pre-BCVA (Log MAR).

\begin{tabular}{|c|c|c|c|c|c|c|}
\hline Variable & Studied groups & N & Mean & $\begin{array}{c}\text { Std. } \\
\text { Deviation }\end{array}$ & $\mathrm{t}$ & p-value \\
\hline \multirow{2}{*}{$\begin{array}{c}\text { pre-BCVA (Log } \\
\text { MAR) }\end{array}$} & $\begin{array}{c}\text {-group A no IVB } \\
\text { injection }\end{array}$ & 10 & 1.910 & 0.2283 & 0.094 & 0.927 \\
\cline { 2 - 7 } & $\begin{array}{c}\text {-group B IVB } \\
\text { injection }\end{array}$ & 10 & 1.900 & 0.2494 & & \\
\hline
\end{tabular}

\section{Postoperative Best Corrected Visual Acuity} (BCVA):

At 1 week, the mean BCVA (log MAR) improved to $1.260 \pm 0.433$ and $1.260 \pm 0.347$ in Group A and B, respectively with no statistically significant difference between the two groups ( $p$ $>1.000$ ). A significant improvement in the mean BCVA was observed at 1 month in all groups. The mean BCVA (log MAR) improved to $1.100 \pm$ 0.2309 and.0980 \pm 0.1932 in Group $\mathrm{A}$ and $\mathrm{B}$, respectively with no statistically significant difference between the two groups $(p=0.224)$.

The final BCVA $(\log$ MAR) at 3 months significantly improved to $1.080 \pm 0.2098$ and 0.870 \pm 0.17767 in Group A and B, respectively, with statistically significant difference between the two groups ( $p>0.027$ ) (Table 4).

Table 4: Mean difference between the studied groups as regard post-BCVA (Log MAR).

\begin{tabular}{|c|c|c|c|c|c|c|}
\hline Variables & Studied Groups & $\mathbf{N}$ & Mean & $\begin{array}{c}\text { Std. } \\
\text { Deviation }\end{array}$ & $t$ & P-value \\
\hline $\begin{array}{l}\text { post BCVA } 1 \\
\text { week }\end{array}$ & \begin{tabular}{|l}
-group A no \\
IVB injection \\
-group B IVB \\
injection
\end{tabular} & $\begin{array}{l}10 \\
10\end{array}$ & $\begin{array}{l}1.260 \\
1.260\end{array}$ & $\begin{array}{l}0.433 \\
0.347\end{array}$ & 0.000 & 1.000 \\
\hline \multirow{2}{*}{$\begin{array}{l}\text { post BCVA } \\
\text { *1Month }\end{array}$} & \begin{tabular}{|l} 
group A no \\
IVB injection \\
\end{tabular} & 10 & 1.100 & .2309 & 1.260 & 0.224 \\
\hline & $\begin{array}{l}\text {-group B IVB } \\
\text { injection }\end{array}$ & 10 & .980 & .1932 & & \\
\hline \multirow{2}{*}{$\begin{array}{l}\text { post BCVA } \\
\text { *3Month }\end{array}$} & $\begin{array}{l}\text {-group A no } \\
\text { IVB injection }\end{array}$ & 10 & 1.080 & .2098 & 2.421 & 0.027 \\
\hline & $\begin{array}{l}\text {-group B IVB } \\
\text { injection }\end{array}$ & 10 & .870 & .1767 & & \\
\hline
\end{tabular}

Mean differences between pre-BCVA (Log MAR) - post BCVA (Log MAR) among the studied groups:

At 1 week, the mean BCVA (log MAR) improved to $0.645 \pm 0.503$ with statistically significant difference between the two groups ( $\mathrm{p}$ $>0.000$ ) (Table 5). At 1 month the mean differences between pre-BCVA (Log MAR) and post BCVA (Log MAR) among the studied groups was $0.865 \pm 0.351$ with statistically significant difference between the two groups $(\mathrm{p}=0.000)$ (Table 6).The final mean differences between preBCVA (Log MAR) and post BCVA (Log MAR) among the studied groups at 3 months was $0.930 \pm$ 0.34 with statistically significant difference between the two groups $(\mathrm{p}=0.000)$ (Table 7).

Table 5: Mean differences between pre-BCVA (Log MAR) - post BCVA (Log MAR) among the studied groups at 1 week.

\begin{tabular}{|c|c|c|c|c|c|}
\hline Variable & N & Mean & $\begin{array}{c}\text { Std. } \\
\text { Deviation }\end{array}$ & t & $\begin{array}{c}\text { Sig. } \\
(\mathbf{2}- \\
\text { tailed) }\end{array}$ \\
\hline $\begin{array}{c}\text { pre-BCVA (Log MAR) } \\
\text { - post BCVA 1Week }\end{array}$ & 20 & 0.645 & 0.503 & 5.73 & 0.001 \\
\hline
\end{tabular}

Table (6): Mean differences between pre-BCVA (Log MAR) - post BCVA (Log MAR) among the studied groups at 1 month.

\begin{tabular}{|l|c|c|c|c|c|}
\hline \multicolumn{1}{|c|}{ Variable } & N & Mean & $\begin{array}{c}\text { Std. } \\
\text { Deviation }\end{array}$ & $\mathbf{t}$ & $\begin{array}{c}\text { Sig. } \\
(\mathbf{2}- \\
\text { tailed) }\end{array}$ \\
\hline $\begin{array}{l}\text { pre-BCVA (Log } \\
\text { MAR) - post BCVA } \\
\text { 1month }\end{array}$ & 20 & 0.865 & .351 & 11.01 & 0.001 \\
\hline
\end{tabular}


Table (7): Mean differences between pre-BCVA (Log MAR) - post BCVA (Log MAR) among the studied groups at 3 month.

\begin{tabular}{|l|c|c|c|c|c|}
\hline \multicolumn{1}{|c|}{ Variable } & N & Mean & $\begin{array}{c}\text { Std. } \\
\text { Deviation }\end{array}$ & t & $\begin{array}{c}\text { Sig. } \\
(\mathbf{2 -} \\
\text { tailed) }\end{array}$ \\
\hline $\begin{array}{l}\text { pre-BCVA (Log } \\
\text { MAR) - post BCVA } \\
\text { 3month }\end{array}$ & 20 & .930 & 0.34 & 12.27 & 0.001 \\
\hline
\end{tabular}

\section{Post-operative complications:}

Regarding incidence of post-operative vitreous hemorrhage at 3 months, there were 8 eyes $(80 \%)$ and 6 eyes $(60 \%)$ had clear media in group A and group B respectively, with no statistically significant difference between the two groups $(\mathrm{P}=0$. 237). Regarding cataract progression, there were 3 eyes $(30 \%)$ and 4 eyes $(40 \%)$ had cataract progression in group A and group B respectively, with no statistically significant difference between the two groups $(\mathrm{P}=0.500)$ (Table 8).

Table (8): Postoperative complications.

\begin{tabular}{|l|c|c|c|}
\hline \multirow{2}{*}{ Variables } & \multicolumn{3}{|c|}{ Studied groups } \\
\cline { 2 - 4 } & $\begin{array}{c}\text { Group A no IVB } \\
\text { injection } \\
\text { N=10 (100\%) }\end{array}$ & $\begin{array}{c}\text { Group B IVB } \\
\text { injection } \\
\text { N=10 (100\%) }\end{array}$ & $\begin{array}{c}\text { Test of } \\
\text { significance }\end{array}$ \\
\hline $\begin{array}{l}\text { Incidence of post } \\
\text { VH 3Month }\end{array}$ & $8(80 \%)$ & $10(100 \%)$ & Chi-q=2.22 \\
-Clear & $2(20 \%)$ & $0(0.0 \%)$ & $\mathrm{P}=0.237$ \\
-VH & $7(70 \%)$ & $6(60 \%)$ & Chi-sq=.220 \\
\hline Cataract progress: & $3(30 \%)$ & $4(40 \%)$ & $\mathrm{P}=0.500$ \\
-not progress & -progress & \multicolumn{2}{|c|}{} \\
\hline
\end{tabular}

Correlation (r) the studied groups and severity of $\mathrm{VH}$ after 1week, 1month and 3 month of operation:

Table 9: Relation between the studied groups as regards the severity of VH after 1 week, 1month and 3 months postoperatively.

\begin{tabular}{|c|c|c|c|}
\hline $\begin{array}{l}\text { - Group A no IVB injection }(n=10) \\
\text {-Group B IVB injection }(n=10)\end{array}$ & $\mathbf{N}$ & $\mathbf{r}$ & Sig. \\
\hline Severity of VH 1 Week & \multirow{3}{*}{20} & -0.275 & 0.241 \\
\hline Severity of VH 1Month & & -0.180 & 0.449 \\
\hline Severity of VH 3Month & & -0.314 & 0.177 \\
\hline
\end{tabular}

Table 9: Demonstrates the correlation between both studied groups and severity of postoperative $\mathrm{VH}$ where no statistical significant relation after 1 week, 1 month and 3months $(\mathrm{r}=$ $0.275,-0.180,-0.314)$ and $(\mathrm{p}=0.241,0.449,0.177)$ respectively.
Correlation (r) the studied groups and incidence of post $\mathrm{VH}$ after 1week, 1month and 3 month of operation:

Table 10: Relation between the studied groups as regards the incidence of post VH after 1 week, 1 month and 3 month of operation.

\begin{tabular}{|l|c|c|c|}
\hline $\begin{array}{l}\text { - Group A no IVB injection (n=10) } \\
\text {-Group B IVB injection(n=10) }\end{array}$ & \multirow{2}{*}{ N } & r & Sig. \\
\hline Incidence of post VH 1Week & \multirow{2}{*}{20} & -0.204 & 0.388 \\
\cline { 1 - 2 } \cline { 4 - 5 } & & -0.115 & 0.628 \\
\cline { 1 - 1 } Incidence of post VH 1Month & -0.333 & 0.151 \\
\hline
\end{tabular}

Table 10: Shows the correlation between both studied groups and incidence of post-operative VH where no statistical significant relation after 1 week, 1 month and 3months $(\mathrm{r}=-0.204,-0.115$, $0.333)$ and $(\mathrm{p}=0.388,0.628,0.151)$ respectively.

\section{DISCUSSION}

Our study was designed to compare the efficacy of intraoperative IVB injection in preventing early postoperative vitreous hemorrhage following pars plana vitrectomy for complications of PDR. The study included 20 eyes of 20 patients undergoing PPV for severe non-clearing vitreous hemorrhage for more than one month. These eyes were randomly assigned to one of two groups:

1. Group A (control group), no IVB injection at the end of vitrectomy.

2. Group B, with IVB injection at the end of vitrectomy.

In Group A, 10 eyes did not receive any intravitreal injection and in Group B, 10 eyes received $1.25 \mathrm{mg}$ IVB injection at the end of surgery.

In the current study, comparison between the two groups revealed that adjunctive use of IVB intraoperatively, did not significantly reduce the incidence of postoperative VH. At 1 month after surgery, the incidence of early postoperative $\mathrm{VH}$ was $30 \%$ and $20 \%$ in Group A and B, respectively $(\mathrm{p}=0.641)$. Mild vitreous hemorrhage (grade 1) was the major component of early $\mathrm{VH}$ at 1 month (20\% of $30 \%$ and $10 \%$ of $20 \%$, in Group A and B, respectively). As can be expected, mild $\mathrm{VH}$ resulted in mild visual deterioration during its presence and also cleared up much faster, having relatively little impact on the final visual outcome.

In our study, peripheral vitrectomy and vitreous base shaving with scleral indentation were performed to prevent dispersion of residual blood, 
and all eyes were left on air which acts as tamponade. Also, complete removal of fibrovascular tissues and meticulous hemostasis may have contributed to reducing the overall incidence of early postoperative $\mathrm{VH}$ regardless of IVB use.

At 3 months after surgery, the incidence of late postoperative $\mathrm{VH}$ was $20 \%$ and $0.00 \%$ in Group A and B, respectively, with no significant difference between the two groups $(\mathbf{p}=\mathbf{0 . 2 3 7})$. Also, the current study showed significant difference in the mean BCVA between the two groups at 3 months $(\mathbf{p}=\mathbf{0 . 0 2 7})$. Effects of IVB are known to be transient, with a reported aqueous half-life of 9.82 days after $1.5 \mathrm{mg}$ IVB injection in human nonvitrectomized eyes ${ }^{(\mathbf{1 0})}$.

As clearance of intravitreally injected bevacizumab is enhanced in vitrectomized eyes, the anti-VEGF effect of IVB injected at the end of surgery would last for even a shorter time ${ }^{(\mathbf{1 1 1})}$. Thus, although IVB injected at the end of surgery may exert its anti-VEGF effect during the early postoperative period, this effect would be minimal at 3 months after surgery, resulting in late $\mathrm{VH}$ incidence and final visual outcome similar to those of the control group but in our study the final improvement in BCVA at 3 months can be explained by the other effects of the bevacizumab such improving the macular edema associated with diabetic retinopathy ${ }^{(12)}$.

It is also well-known that after vitrectomy, as the vitreous gel is replaced with the less viscous balanced salt solution, air or sulfur hexafluoride gas and eventually aqueous humor, the transport of all molecules is improved, including that of oxygen, VEGF and other cytokines ${ }^{(13)}$. Although PPV and laser photocoagulation improve retinal oxygenation, VEGF surge induced by surgery can stimulate iris neovascularization or fibrovascular proliferation that may eventually lead to postoperative VH. With IVB injection at the end of surgery, VEGF surge is expected to be antagonized more effectively, inhibiting retinal and iris neovascularization and fibrovascular proliferation, and thus reducing the incidence of postoperative VH. Inhibition of VEGF activity is also known to cause relative vasoconstriction. Intravitreal bevacizumab injected at the end of surgery may induce vasoconstriction of the fragile retinal vessels injured during surgery, bringing about effects similar to vessel regression, thus preventing another bleeding focus from causing postoperative $\mathrm{VH}^{(\mathbf{1 4}) \text {. }}$
Cheema et al. ${ }^{(15)}$ reported significantly reduced incidence of recurrent postoperative $\mathrm{VH}$ in patients who received $1.25 \mathrm{mg}$ of IVB at the end of diabetic vitrectomy compared with controls $(4.0 \%$ vs. 42.4\%; $\mathrm{p}=0.001)$. Park et al. ${ }^{(16)}$ evaluated the clinical outcome and complications of intravitreal bevacizumab (IVB) versus triamcinolone acetonide (IVT) injections at the end of vitrectomy in 156 eyes with diabetic VH. They reported significantly lower rates of early postoperative VH in the IVB and IVT groups than in the control group $(12.1 \%, 9.1 \%$ and $36.8 \%$, respectively; $\mathrm{p}=0.002$ and $\mathrm{p}=0.006$, respectively), although there was no significant difference in the rates of late postoperative $\mathrm{VH}$ between the three groups $(p=0.341)$. However, both these studies were limited by their retrospective nature and lack of randomization.

On the contrary, some studies have suggested that IVB injection at the end of diabetic vitrectomy did not influence the rates of postoperative VH. In a prospective pilot study, Romano et al. ${ }^{(17)}$ evaluated the recurrence rate of $\mathrm{VH}$ in 30 eyes that received 2.5 $\mathrm{mg}$ of IVB at the end of vitrectomy for the treatment of diabetic non-clearing $\mathrm{VH}$. The incidence of severe recurrent $\mathrm{VH}$ with no fundus details (grade 3) was $7 \%, 13 \%, 27 \%$, and $30 \%$ at 7 days, 1 month, 3 months, and 6 months after surgery, respectively. They concluded that IVB injection at the end of surgery cannot prevent rebleeding in eyes undergoing PPV for the treatment of diabetic VH. However, that study was limited by its lack of a control group.

The first prospective randomized clinical trial to compare the effects of preoperative versus intraoperative IVB injection on reducing postoperative $\mathrm{VH}$ was carried out by Ahn et al. ${ }^{(18)}$ who randomly assigned 107 eyes of 91 patients to three groups: group 1 received $1.25 \mathrm{mg}$ IVB injection 1 to 14 days before PPV for complications of PDR; group 2 received $1.25 \mathrm{mg}$ IVB injection at the end of surgery; and group 3 did not receive any injection. The incidence of early recurrent VH was $22.2 \%$, $10.8 \%$ and $32.4 \%$ in group 1,2 and 3 , respectively (p $=0.087$ ). Subgroup analysis showed significantly lower incidence of early recurrent $\mathrm{VH}$ in the intraoperative IVB group compared with the control group $(\mathrm{p}=0.026)$. The incidence of late recurrent $\mathrm{VH}$ was $11.1 \%, 16.2 \%$ and $14.7 \%$ in group 1,2 and 3 , respectively, with no significant difference between the three groups $(\mathrm{p}=0.813)$. The initial time of vitreous clearing (ITVC) was significantly shorter in the intraoperative IVB group compared with the 
preoperative IVB and control groups $(\mathrm{p}=0.045$ and $\mathrm{p}$ $=0.015$, respectively). The final BCVA at 6 months after surgery was not significantly different between the three groups $(\mathrm{p}=0.418)$. Also, there was no significant difference in the rate of reoperation for recurrent $\mathrm{VH}$ between the three groups $(\mathrm{p}=1.000)$

Based on these results, the authors found no substantial evidence to support the adjunctive use of preoperative IVB to reduce the postoperative recurrence of VH in vitrectomy for PDR. However, for selected cases in which adjunctive IVB use is considered, intraoperative administration may be the better option for reducing postoperative $\mathrm{VH}$.

In the current study, analysis of changes in the mean BCVA at 1 month and 3 months after surgery showed significant improvement from the preoperative BCVA in all study groups, although there was no significant difference between the two groups at any time point. These results were consistent with those reported by other authors ${ }^{(16,18)}$. However, these results should be interpreted with caution due to different baseline characteristics of the patients such as the presence of macular edema, which is another significant factor affecting visual acuity in DR and it was not assessed in our study. Also, the follow-up period of 3 months was relatively short and evaluation of the longterm effects of IVB on the visual outcome was beyond the scope of our study.

Cataract development or progression is one of the most common complications after vitreoretinal surgery and, if visually significant, a second procedure for cataract extraction will be required. The reported incidence of cataract after vitrectomy varies widely among different studies, ranging from $17 \%$ to $80 \%{ }^{19}$. Several factors can influence the rate of cataract formation after vitrectomy such as age of patient, indication of vitrectomy, use of intraocular gas or silicone oil tamponade, and duration of follow-up. On the other hand study of 301 eyes found that patients aged 50 years or older had 6-fold increase in the rate of cataract formation, and that the use of intraocular gas increased the rate of progression of nuclear sclerosis by $60 \%{ }^{(20)}$. With silicone oil tamponade, the rate of cataract formation may reach $100 \%{ }^{(\mathbf{2 1})}$. Cheng et al. ${ }^{(\mathbf{2 2})}$ reported that the incidence of progression of nuclear sclerosis was $100 \%$ at 2 years after vitrectomy for macular hole, and that duration of surgery did not increase the risk of cataract progression.
In the current study, the incidence of cataract development or progression was $30.0 \%$ and $40.0 \%$ Group A and B, respectively $(\mathrm{p}=0.500)$.

These results were comparable with those reported by Romano et al. ${ }^{(17)}$ who conducted a prospective pilot study to evaluate the effect of IVB injection at the end of vitrectomy on the recurrence rate of $\mathrm{VH}$. They found that $40 \%$ of Phakic eyes developed cataract during the 6-month follow-up period.

Limitations of the current study include few number of cases (10 and 10 in Group A and B, respectively), lack of sham injection in the control group, and a relatively short follow-up period of 3 months. Also, as preoperative vitreous hemorrhage obscured the fundus view in most cases, the severity of PDR was assessed intraoperatively' resulting in differences in the baseline severity of PDR between the study groups and leaving room for possible bias.

\section{CONCLUSIONS}

The incidence of early postoperative vitreous hemorrhage following pars plana vitrectomy for complications of PDR is low and is not affected by intraoperative intravitreal bevacizumab injection.

Mild vitreous hemorrhage is the major component of early postoperative vitreous hemorrhage at one month after surgery, irrespective of intravitreal bevacizumab injection.

The incidence of late postoperative vitreous hemorrhage is lower than that of early postoperative vitreous hemorrhage and is not affected by intraoperative intravitreal bevacizumab injection.

Pars plana vitrectomy for complications of PDR is associated with significant improvement of BCVA, irrespective of intravitreal bevacizumab injection.

Adjunctive use of intravitreal bevacizumab with pars plana vitrectomy for complications of PDR is safe and well-tolerated with no serious ocular or systemic adverse events.

Cataract development or progression is common after pars plana vitrectomy for complications of PDR, irrespective of intravitreal bevacizumab injection.

The duration and type of DM, and type of vitreous substitute do not affect the severity of early post-vitrectomy vitreous hemorrhage. 


\section{REFERENCES}

1. Tolentino FI, Cajita VN, Gancayco $\mathrm{T}$ et al. (1989): Vitreous hemorrhage after closed vitrectomy for proliferative diabetic retinopathy. Ophthalmology, 96(10):1495-500.

2. Selim KM, Sahan D, Muhittin T et al. (2010): Increased levels of vascular endothelial growth factor in the aqueous humor of patients with diabetic retinopathy. Indian $\mathbf{J}$ Ophthalmol., 58(5):375-9.

3. Ferrara $\mathbf{N}$ (2004): Vascular endothelial growth factor: basic science and clinical progress. Endocrinal Review, 25:581-611.

4. Bhavsar AR (2002): Diabetic retinopathy. The diabetes eye exam initiative. Minn Med., 85(6):46-7.

5. Resnikoff S, Pascolini D, Etya'ale D et al. (2004): Global data on visual impairment in the year 2002. Bull World Health Organ, 82(11):844-51.

6. Hershberger VS, Augsburger JJ, Hutchins RK et al. (2004): Fibrovascular ingrowth at sclerotomy sites in vitrectomized diabetic eyes with recurrent vitreous hemorrhage: ultrasound biomicroscopy findings. Ophthalmology, 111(6):1215-21.

7. Matsuoka M, Ogata $\mathrm{N}$, Minamino $\mathrm{K}$ et al. (2006): Expression of pigment epitheliumderived factor and vascular endothelial growth factor in fibrovascular membranes from patients with proliferative diabetic retinopathy. Jpn J Ophthalmol., 50(2):116-20.

8. Avery RL, Pearlman J, Pieramici DJ et al. (2006): Intravitreal bevacizumab (Avastin) in the treatment of proliferative diabetic retinopathy. Ophthalmology, 113(10):1695-705.

9. Charles S, Rosenfeld PJ and Gayer S (2007): Medical consequences of stopping anticoagulant therapy before intraocular surgery or intravitreal injections. Retina, 27:813-815.

10. Krohne TU, Eter N, Holz FG et al. (2008): Intraocular pharmacokinetics of bevacizumab after a single intravitreal injection in humans. Am J Ophthalmol., 146(4):508-12.

11. Kakinoki M, Sawada O, Sawada T et al. (2012): Effect of vitrectomy on aqueous VEGF concentration and pharmacokinetics of bevacizumab in macaque monkeys. Invest Ophthalmol Vis Sci., 53(9):5877-80.
12. Seo JW and Park IW (2009): Intravitreal bevacizumab for treatment of diabetic macular edema. Korean J Ophthalmol., 23(1):17-22.

13. Stefánsson E(2009): Physiology of vitreous surgery. Graefes Arch Clin Exp Ophthalmol.. 247(2):147-63.

14. Ellis LM and Hicklin DJ(2008): VEGFtargeted therapy: mechanisms of anti-tumour activity. Nat Rev Cancer, 8(8):579-91.

15. Cheema RA, Mushtaq J, Al-Khars W et al. (2010): Role of intravitreal bevacizumab (Avastin) injected at the end of diabetic vitrectomy in preventing postoperative recurrent vitreous hemorrhage. Retina, 30(10):1646-50.

16. Park DH, Shin JP and Kim SY (2010): Intravitreal injection of bevacizumab and triamcinolone acetonide at the end of vitrectomy for diabetic vitreous hemorrhage: a comparative study. Graefes Arch Clin Exp Ophthalmol., 248(5):641-50.

17. Romano MR, Gibran SK, Marticorena J et al. (2009): Can an intraoperative bevacizumab injection prevent recurrent postvitrectomy diabetic vitreous hemorrhage? Eur J Ophthalmol., 19(4):618-21.

18. Ahn J, Woo SJ, Chung H et al. (2011): The effect of adjunctive intravitreal bevacizumab for preventing postvitrectomy hemorrhage in proliferative diabetic retinopathy. Ophthalmology, 118(11):2218-26.

19. Cherfan GM, El maghraby AE, Tabbara KF et al. (1991): Dissolution of intraocular fibrinous exudate by streptokinase. Ophthalmology, 98:870-874

20. Thompson JT (2004): The role of patient age and intraocular gas use in cataract progression after vitrectomy for macular holes and epiretinal membranes. Am J Ophthalmol., 137(2):250-7.

21. Federman JL and Schubert HD (1988): Complications associated with the use of silicone oil in 150 eyes after retina-vitreous surgery. Ophthalmology, 95(7):870-6.

22. Cheng L, Azen SP, El-Bradey MH et al. (2001): Duration of vitrectomy and postoperative cataract in the vitrectomy for macular hole study. Am J Ophthalmol., 132(6):881-7. 